Research Paper

\title{
FABPI Polymorphisms Contribute to Hepatocellular Carcinoma Susceptibility in Chinese Population with Liver Cirrhosis: A Case-Control Study
}

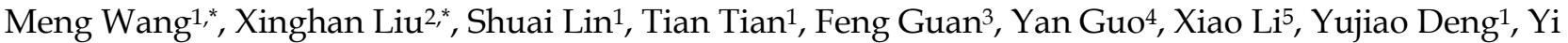 \\ Zheng ${ }^{1}$, Peng Xu ${ }^{1}$, Qian Hao ${ }^{1}$, Zhen Zhai ${ }^{1}$, and Zhijun Dai ${ }^{\circledR}$ \\ 1. Department of Oncology, The Second Affiliated Hospital of Xi'an Jiaotong University, Xi'an 710004, China; \\ 2. School of Life Sciences, Nanjing University, Nanjing 210046, China; \\ 3. School of Life Sciences, Northwest University, Xi'an 710069, China; \\ 4. School of Life Science and Technology, Xi'an Jiaotong University, $\mathrm{Xi}^{\prime}$ an 710049, China; \\ 5. Department of Hepatobiliary Surgery, Xijing Hospital, Fourth Military Medical University, Xi'an 710032, China. \\ *These authors contributed equally to this work. \\ $\square$ Corresponding author: Zhi-Jun Dai, Department of Oncology, The Second Affiliated Hospital of Xi'an Jiaotong University, Xi'an 710004, China (E-Mail: \\ dzj0911@126.com). \\ (1) Ivyspring International Publisher. This is an open access article distributed under the terms of the Creative Commons Attribution (CC BY-NC) license \\ (https:// creativecommons.org/licenses/by-nc/4.0/). See http://ivyspring.com/terms for full terms and conditions.
}

Received: 2018.05.16; Accepted: 2018.08.26; Published: 2018.10.20

\begin{abstract}
Purpose: Single nucleotide variations in the liver fatty acid binding protein ( $L-F A B P, F A B P I)$ gene lead to changes in cellular signaling pathways and lipid metabolism. FABPI polymorphisms were associated with some liver diseases, like steatotic hepatocellular carcinoma. However, the association between FABPI rs1545224 and rs2241883 polymorphisms and hepatitis B virus-related liver cirrhosis (LC) and hepatocellular carcinoma (HCC) has not been reported. We performed this study to explore their relationship.

Methods: One thousand individuals ( 250 healthy controls, 250 chronic HBV (CHB), 250 LC, and $250 \mathrm{HCC}$ patients) were recruited. Odds ratios (ORs) and $95 \%$ confidence intervals ( $95 \% \mathrm{Cls}$ ) were applied to assess the difference in allele and genotype frequencies. Cochran-Armitage trend test was used to evaluate the cumulative effect. Significant difference would be defined when the $P$ value was less than 0.05 .

Results: The distribution of rs1545224 GG, AG and AA genotypes in healthy controls or CHB carriers was not significant when compared to LC or HCC patients $(P>0.05)$. LC patients carrying at least one $A$ allele are more likely to develop HCC in contrast with those with $G$ allele $(P<0.05)$. After adjustment for confounders, meaningful results were only seen in the comparison between rs 1545224 AG+AA genotype carriers and GG genotype carriers among the LC patients $(P<0.05)$. Rs2241883 polymorphism did not influence the risk of developing LC or HCC in healthy and CHB individuals, nor did it influence the risk of HCC in LC patients ( $P>0.05)$.

Conclusions: Taken together, FABPI rs 1545224 polymorphism might increase HCC risk in LC patients, indicating that $F A B P I$ rs 1545224 polymorphism may be related to the process of developing HCC in Chinese patients with LC.
\end{abstract}

Key words: $F A B P 1$, polymorphism, hepatocellular carcinoma, liver cirrhosis

\section{Introduction}

The Hepatitis B virus (HBV), which has double-stranded DNA, can be transmitted by mother-to-child mode, sex, iatrogenic infection, close contact with infected people and blood [1]. An estimated 257 million people worldwide carry chronic $\mathrm{HBV}$, and about 893,333 people died of $\mathrm{HBV}$ and 
HBV-induced complications, such as liver cirrhosis (LC) or hepatocellular carcinoma (HCC) in 2015 [2]. Of these infected persons, less than $10 \%$ were diagnosed, and only $0.7 \%$ received treatment [2]. As the most affected area by HBV infection, the incidence and mortality of HCC ranked fourth and third in China in 2015 respectively [3]. Vaccines and antiviral drugs are widely used to decrease HBV incidence, clear HBV infection and control the progression of related liver diseases. Although these efforts have led to tremendous achievements, the huge gaps between diagnosis and treatment are still big challenges to the management of $\mathrm{HBV}$ infections. HBV contributed $47.2 \%$ and $48.5 \%$ to viral hepatitis-related mortality and disability-adjusted life-years respectively, in 2013 [4]. Most of the times, liver cancer and cirrhosis account for the majority of mortality and are mainly concentrated in sub-Saharan Africa and most of Asia. Viral, environmental and host factors play important roles during disease progression. Different $\mathrm{HBV}$ genotypes have distinct seroconversion times, resulting in differential risk and prognosis of liver disease [5]. Smoking, alcohol consumption and exposure to aflatoxin increases the risk of LC or HCC in HBV patients [6]. Genes involved in viral mutation, host response and other aspects also influence the course of $\mathrm{HBV}$-associated liver diseases. IFNLR1 rs4649203, rs7525481 and IFNAR2 rs1051393, rs12233338 polymorphisms were associated with HBV infection, while IFNA1 rs1831583 and IFNA2 rs649053 were associated with the development of HCC [7]. Rs10272859 at 7q21.13, identified by a genome-wide association study, was found to contribute to the susceptibility and prognosis of HBV-related HCC, and the CDK14 gene was suggested as the probable target of the locus [8].

The gene encoding the liver fatty acid binding protein $(L-F A B P, F A B P 1)$, located at chr 2p12-q11, is expressed in the intestine, liver, pancreas, stomach and kidney [9]. Because of its abundant expression, high binding abilities, and unique function, FABP1 regulates a variety of cellular processes including inflammation, immunity, metabolism and energy homeostasis [10]. A number of recent studies have focused on its role in liver diseases. Mukai $\mathrm{T}$ et al. found a reduction in liver weight and hepatic triglycerides in FABP1 knockdown mice, fed with a high fat diet. They also observed that the levels of hepatic inflammation cytokines and chemokines (interleukin-6, tumor necrosis factor alpha, and monocyte chemotactic protein 1) and an oxidative stress maker (heme oxygenase-1) were significantly reduced in this mouse model [11]. FABP1 T94A substitution induced increased hepatic lipid, and alterations in hepatic endocannabinoids system in males, which suggested an important role of $F A B P 1$ in nonalcoholic fatty liver disease (NAFLD) [12]. Several studies indicated a relationship between hepatic steatosis and HBV infection [13-15]. Elevated FABP1 expression was found in the serum of HBV patients and overexpression of HBV X protein lead to FABP1 upregulation, both in vitro and vivo, suggesting the potential therapeutic value of FABP1 inhibition in steatosis-related chronic HBV infection [13]. Immunohistochemical staining showed higher FABP1 expression in HCC tissues than normal adjacent tissues [16]. FABP1 could induce HCC cell migration through FAK/cdc42 pathway in vitro, and promote tumor growth and metastasis in vivo [16].

According to the research findings, we guess FABP1 gene may be associated with HBV infection and HCC. However, its function in HBV-associated LC and HCC has not been studied. Two polymorphisms (rs1545224 G/A and rs2241883 T/C) in $F A B P 1$ gene were found to influence susceptibility to NAFLD in Chinese population [17]. However, their roles in HBV-related liver disease have not been discussed [18-21]. Our purpose was to figure out the association between FABP1 rs1545224 and rs2241883 polymorphisms and the susceptibility of HBV-related LC and HCC in the northwestern Chinese population.

\section{Materials and Methods}

\section{Ethics statement}

Our research sought the consent of the Ethics Committee of the Second Affiliated Hospital of Xi'an Jiaotong University (Xi'an, China) and conducted following the approved guidelines.

\section{Study population}

1000 individuals, consisting of 250 healthy people, 250 patients carrying $\mathrm{CHB}, 250$ patients with LC and 250 patients with HCC, were recruited from the Second Affiliated Hospital of Xi'an Jiaotong University, and Xijing Hospital of Fourth Military Medical University, Xi'an, Shaanxi Province, China in this study. $\mathrm{CHB}$ carriers need to meet these criteria: 1) Serum HBsAg and HBV DNA, HBeAg or anti-HBe should be positive; 2) Serum alanine transaminase (ALT) and aspartate aminotransferase (AST) levels should continue normal in one year; 3) Liver histological examination had no obvious abnormality or histologicalactivity index (HAI) score $<4$. Inclusion criteria for LC patients were as follows: 1) The history of HBV; 2) Patients were confirmed as LC by pathology; 3) Patients without pathological diagnosis required the presence of portal hypertension and hepatic dysfunction and were confirmed by ultrasound or CT. In addition to the history of HBV, patients with HCC need to be confirmed by 
pathology. Healthy controls were outpatients who seek for medical examination at the two hospitals. Basic information such as age, race, smoking, drinking and medical histories were collected by interview. We also collected blood samples after interview.

\section{Genotyping assay}

After centrifugation, blood samples were placed in $-80^{\circ} \mathrm{C}$ refrigerators. We extracted and concentrated the genomic DNA from samples according to the methods in our previous studies [22, 23]. We selected rs1545224 and rs2241883 polymorphisms to explore the association, genotyped them by the Sequenom MassARRAY RS1000 and analyzed the data by Sequenom Type 4.0. Primers used are shown in Table 1.

Table 1. Primers used in this study

\begin{tabular}{llll}
\hline SNP_ID & 1st-PCRP & 2nd-PCRP & UEP_SEQ \\
\hline rs1545224 & ACGTTGGATGGCAC & ACGTTGGATGTCTGTG & CGCTGAGCAGA \\
& TTACTGAGGATCCA & GCTGGTTGGTGC & AAGG \\
& TC & & \\
rs2241883 & ACGTTGGATGGACA & ACGTTGGATGGTGATT & TAACAGACTTG \\
& GTGGTTCAGTTGGA & ATGTCGCCGTTGAG & ATGTTTTTGAA \\
& AG & & AG \\
\hline
\end{tabular}

\section{Statistical analyses}

SPSS software package (version 20.0; SPSS Inc., Chicago, IL, USA) was adopted to process data. To evaluate whether the control group meets HWE, we compared the expected and observed frequencies by Alrlquin 3.1 program (L. Excoffier, CMPG, University of Bern, Switzerland). Pearson's $\chi^{2}$ test was applied to calculate the frequency difference in the allele and genotypes of the four groups under four models including the codominant, dominant, recessive and allele models. Cochran-Armitage trend test was used to evaluate the cumulative effect. The results were presented as ORs, 95\% CIs and $P$ values. Significant difference would be defined when the bilateral $P$ value was less than 0.05 .

\section{Results}

\section{Basic information of the study population}

We recruited four distinct groups consisting of healthy people, chronic HBV (CHB), HBV-positive LC or HBV-positive HCC patients, respectively (Table 2). Each group had 250 individuals and had no significant difference in average age or gender compared with the other groups $(P=0.056$ and 0.051 , respectively). Considering the influence of life habits, we found that people with alcohol or diabetes history accounted for a greater proportion in $\mathrm{CHB}, \mathrm{LC}$ and HCC groups than in controls $(P=0.002$ and 0.021 , respectively), whereas smoking history and family history did not differ in the four groups $(P=0.100$ and 0.647 , respectively). Liver injury markers, including T-Bil, ALT, AST, and alpha fetoprotein (AFP) were present at higher levels in $\mathrm{HBV}$-positive patients than in healthy individuals $(P<0.001)$.

As displayed in Table 3, the included control group met the Hardy-Winberg equilibrium (HWE) and could represent the general population. For FABP1 rs1545224 polymorphism, the frequencies of individuals with GG, AG, and GG genotypes were $30.4 \%, 45.6 \%$, and $24.0 \%$ respectively, among the disease free controls; $29.7 \%, 47.0 \%$ and $23.3 \%$ respectively, in $\mathrm{CHB}$ group; $33.6 \%, 46.4 \%$ and $20 \%$ respectively, in LC group; $23.6 \%, 52.4 \%$ and $24.0 \%$ in HCC group, respectively. For rs2241883 polymorphism, the individuals with TT, CT and CC genotype were 149,86 and 13 respectively, in the control group; 153, 87 and 10 respectively, in the CHB group; 165, 77 and 8 respectively, in LC group; 155, 79 and 15 in HCC group, respectively (Table 3 ).

Table 2. Characteristics of including subjects

\begin{tabular}{|c|c|c|c|c|c|}
\hline Characteristics & $\begin{array}{l}\text { Healthy } \\
\text { controls }\end{array}$ & CHB & $\begin{array}{l}\text { CHB-related } \\
\text { LC }\end{array}$ & $\begin{array}{l}\text { CHB-related } \\
\text { HCC }\end{array}$ & $P$ \\
\hline Total number & 250 & 250 & 250 & 250 & \\
\hline $\begin{array}{l}\text { Age (mean } \pm \\
\text { SD) }\end{array}$ & $55.71 \pm 9.17$ & $54.17 \pm 10.37$ & $53.12 \pm 10.58$ & $54.47 \pm 12.00$ & 0.056 \\
\hline \multicolumn{6}{|l|}{ Gender } \\
\hline Male & 201 & 182 & 177 & 194 & 0.051 \\
\hline Female & 49 & 68 & 73 & 56 & \\
\hline \multicolumn{6}{|l|}{ Alcohol history } \\
\hline yes & 22 & 53 & 39 & 42 & 0.002 \\
\hline no & 228 & 197 & 211 & 208 & \\
\hline \multicolumn{6}{|l|}{ Smoking history } \\
\hline yes & 145 & 137 & 118 & 131 & 0.100 \\
\hline no & 105 & 113 & 132 & 119 & \\
\hline \multicolumn{6}{|l|}{ Diabetes history } \\
\hline Yes & 22 & 30 & 39 & 44 & 0.021 \\
\hline no & 228 & 220 & 211 & 206 & \\
\hline \multicolumn{6}{|l|}{ Family history } \\
\hline Yes & 8 & 7 & 12 & 10 & 0.647 \\
\hline No & 242 & 243 & 238 & 240 & \\
\hline \multicolumn{6}{|c|}{ Laboratory parameters } \\
\hline $\begin{array}{l}\text { T-Bil level } \\
\text { (umol/L) }\end{array}$ & $8.49 \pm 4.09$ & $14.35 \pm 5.29$ & $39.22 \pm 11.58$ & $36.76 \pm 10.11$ & $<0.001$ \\
\hline $\operatorname{ALT}(\mathrm{U} / \mathrm{L})$ & $15.36 \pm 5.27$ & $65.33 \pm 13.40$ & $63.84 \pm 21.26$ & $71.03 \pm 16.50$ & $<0.001$ \\
\hline AST (U/L) & $12.35 \pm 4.05$ & $49.62 \pm 15.16$ & $47.99 \pm 24.83$ & $58.21 \pm 17.55$ & $<0.001$ \\
\hline $\operatorname{AFP}(\mathrm{ng} / \mathrm{ml})$ & No data & $7.94 \pm 3.31$ & $43.43 \pm 29.46$ & $1629.59 \pm 625.28$ & $<0.001$ \\
\hline $\begin{array}{l}\text { Number of } \\
\text { patients with } \\
\mathrm{AFP} \leq 400 \\
\mathrm{ng} / \mathrm{ml}\end{array}$ & - & - & - & 156 & \\
\hline
\end{tabular}

alanine transaminase; AST, aspartate aminotransferase; AFP, alpha-fetoprotein.

\section{Association between FABPI polymorphisms and the risk of LC}

As shown in Table 4, we observed no statistical difference in the frequency of rs1545224 GG, AG and AA genotypes between healthy subjects and LC patients (AG vs. GG: $\mathrm{OR}=0.92,95 \% \mathrm{CI}=0.61-1.38, P$ 
$=0.69$; AA vs. GG: $\mathrm{OR}=0.75,95 \% \mathrm{CI}=0.46-1.23, P=$ 0.26). This trend was also observed between $\mathrm{CHB}$ carriers and LC patients (AG vs. GG: OR $=1.48,95 \%$ $\mathrm{CI}=0.97-2.26, P=0.07$; AA vs. $\mathrm{GG}: \mathrm{OR}=1.29,95 \% \mathrm{CI}$ $=0.79-2.11, P=0.31$ ). After adjusting for confounding factors including smoking and alcohol status, gender, and age, the results had no meaningful changes (Table 5). The rs2241883 polymorphism, irrespective of adjustments for compounding factors, had no influence on the susceptibility of controls or CHB carriers to LC $(P>0.05)$.

\section{Association between FABPI polymorphisms and the risk of $\mathrm{HCC}$}

As against individuals carrying the GG genotype, healthy individuals with rs1545224 AG and AA genotypes respectively, had 1.48 and 1.29 times the risk of developing HCC (Table 3). In spite of the striking difference, this observation was not significant as the $P$ values were over 0.05 (AG vs. GG: 95\% CI $=0.97-2.26, P=0.07$; AA vs. GG: $95 \% \mathrm{CI}=$ 0.79-2.11, $P=0.31$ ). Rs1545224 AG and AA genotypes also increased the risk of $\mathrm{HCC}$ in the $\mathrm{CHB}$ group (Table 4, AG vs. GG: OR = 1.40; AA vs. GG: OR = 1.30), but the results were not statistically significant (AG vs. GG: $95 \% \mathrm{CI}=0.92-2.14, P=0.12$; AA vs. GG: $95 \% \mathrm{CI}=0.79-2.13, P=0.30)$. Even after correction, the results did not change significantly (Table $5, \mathrm{P}>0.05$ ). Similar to rs1545224, TT, CT and CC genotypes of rs 2241883 polymorphism accounted for $60.1 \%$, 34.7\% and $5.2 \%$ respectively, in the controls, $61.2 \%, 34.8 \%$ and $4.0 \%$ respectively, in the $\mathrm{CHB}$ group, and $62.3 \%$, $31.7 \%$ and $6.0 \%$ respectively, in the HCC group, with no significant difference (Table 3 and 4), irrespective of adjustments (Table 5).

\section{Association between FABPI polymorphisms and the susceptibility of progression from LC to HCC}

LC individuals with at least one rs1545224 A allele were more likely to develop HCC (Table 4, A vs. G: $\mathrm{OR}=1.33,95 \% \mathrm{CI}=1.03-1.79, P=0.03$; AG vs. GG: $\mathrm{OR}=1.61,95 \% \mathrm{CI}=1.06-2.44, P=0.03$; AA vs. GG: $\mathrm{OR}$ $=1.71,95 \% \mathrm{CI}=1.03-2.82 P=0.04 ; \mathrm{AG}+\mathrm{AA}$ vs. $\mathrm{GG}$ : $\mathrm{OR}=1.64,95 \% \mathrm{CI}=1.11-2.43, P=0.01)$. Moreover, Cochran-Armitage trend test revealed that, with an increase in the number of A allele, the risk of HCC increased $(P=0.03)$. In individuals with LC having the AG and AA genotypes, factors like smoking and drinking status, gender, and age, did influence the susceptibility to HCC (Table 5, AG vs. GG: OR $=1.57$, 95\% CI $=0.99-2.49, P=0.06$; AA vs. GG: $\mathrm{OR}=1.63$, $95 \% \mathrm{CI}=0.93-2.85, P=0.09)$. However, $r \mathrm{~s} 2241883$ polymorphism had no significant influence on LC patients to progress to HCC (Table 4 and 5).
Table 3. Allele and genotype distributions of rs 1545224 and rs2241883 polymorphisms in health controls, CHB, LC and HCC patients

\begin{tabular}{|c|c|c|c|c|c|}
\hline \multirow{2}{*}{\multicolumn{3}{|c|}{$\begin{array}{l}\text { Model } \\
\text { rs1545224 HWE }(P=0.18)\end{array}$}} & CHB (n, \%) & LC (n, \%) & HCC $(n, \%)$ \\
\hline & & & & & \\
\hline \multirow[t]{2}{*}{ Allele } & & $266(53.2 \%)$ & $265(53.2 \%)$ & $284(56.8 \%)$ & $249(49.8 \%)$ \\
\hline & A & $234(46.8 \%)$ & $233(46.8 \%)$ & $216(43.2 \%)$ & $251(50.3 \%)$ \\
\hline \multirow{3}{*}{$\begin{array}{l}\text { Codominant } \\
\text { model }\end{array}$} & GG & $76(30.4 \%)$ & $74(29.7 \%)$ & $84(33.6 \%)$ & $59(23.6 \%)$ \\
\hline & AG & $114(45.6 \%)$ & $117(47.0 \%)$ & $116(46.4 \%)$ & $131(52.4 \%)$ \\
\hline & AA & $60(24.0 \%)$ & $58(23.3 \%)$ & $50(20 \%)$ & $60(24.0 \%)$ \\
\hline \multirow{2}{*}{$\begin{array}{l}\text { Dominant } \\
\text { model }\end{array}$} & GG & $76(30.4 \%)$ & $74(29.7 \%)$ & $84(33.6 \%)$ & $59(23.6 \%)$ \\
\hline & $\mathrm{AG}+\mathrm{AA}$ & $174(69.6 \%)$ & $175(70.3 \%)$ & $166(66.4 \%)$ & $191(76.4 \%)$ \\
\hline \multirow{2}{*}{$\begin{array}{l}\text { Recessive } \\
\text { model }\end{array}$} & AG+GG & $190(76.0 \%)$ & $191(76.7 \%)$ & $200(80 \%)$ & $190(76.0 \%)$ \\
\hline & AA & $60(24.0 \%)$ & $58(23.3 \%)$ & $50(20 \%)$ & $60(24.0 \%)$ \\
\hline \multicolumn{6}{|c|}{ rs2241883 HWE $(P=0.90)$} \\
\hline \multirow[t]{2}{*}{ Allele } & $\mathrm{T}$ & $384(77.4 \%)$ & $393(78.6 \%)$ & $407(81.4 \%)$ & $389(78.1 \%)$ \\
\hline & C & $112(22.6 \%)$ & $107(21.4 \%)$ & $93(18.6 \%)$ & $109(21.9 \%)$ \\
\hline \multirow{3}{*}{$\begin{array}{l}\text { Codominant } \\
\text { model }\end{array}$} & TT & $149(60.1 \%)$ & $153(61.2 \%)$ & $165(66.0 \%)$ & $155(62.3 \%)$ \\
\hline & $\mathrm{CT}$ & $86(34.7 \%)$ & $87(34.8 \%)$ & $77(30.8 \%)$ & $79(31.7 \%)$ \\
\hline & $\mathrm{CC}$ & $13(5.2 \%)$ & $10(4.0 \%)$ & $8(3.2 \%)$ & $15(6.0 \%)$ \\
\hline \multirow{2}{*}{$\begin{array}{l}\text { Dominant } \\
\text { model }\end{array}$} & TT & $149(60.1 \%)$ & $153(61.2 \%)$ & $165(66.0 \%)$ & $155(62.3 \%)$ \\
\hline & $\mathrm{CT}+\mathrm{CC}$ & $99(39.9 \%)$ & $97(38.8 \%)$ & $85(34.0 \%)$ & $94(37.7 \%)$ \\
\hline \multirow{2}{*}{$\begin{array}{l}\text { Recessive } \\
\text { model }\end{array}$} & $\mathrm{CT}+\mathrm{TT}$ & $235(94.8 \%)$ & $240(96.0 \%)$ & $242(96.8 \%)$ & $234(94.0 \%)$ \\
\hline & $\mathrm{CC}$ & $13(5.2 \%)$ & $10(4.0 \%)$ & $8(3.2 \%)$ & $15(6.0 \%)$ \\
\hline
\end{tabular}

$\mathrm{HWE}=$ hardy-weinberg equilibrium, $\mathrm{CHB}=$ chronic hepatitis $\mathrm{B}, \mathrm{LC}=$ liver cirrhosis, $\mathrm{HCC}=$ hepatocellular carcinoma

\section{Discussion}

At the genome level, a single nucleotide variation may result in a DNA sequence polymorphism, which named single nucleotide polymorphisms (SNPs). It is the most common type of heritable variation in humans, accounting for nearly 10 million in the human genome [24]. SNPs were reported to be involved in HBV-related liver diseases. Zhang X et al. observed that, in healthy controls, the ghrelin rs26311 GC+CC genotype increased the risk of LC in contrast to the GG genotype $(P=0.034)$, especially in males $(P$ $=0.042)$ [25]. Healthy individuals carrying toll-like receptor 3 (TLR3) rs3775290 TT genotype had a decreased risk for $\mathrm{CHB}, \mathrm{HBV}$-related LC and HCC [26]. Recent genome-wide association studies and cohort studies confirmed that the SNPs in signal transducer and activator of transcription 4 (STAT4), $\mathrm{C} 2$, human leucocyte antigen (HLA)-DRB1 and HLADQ were related to HBV-related HCC and HBVrelated LC, indicating SNPs may participate in the progression of $\mathrm{CHB}$ to HCC and CHB to LC $[27,28]$.

As a result of its function in cell signaling pathways and lipid metabolism, FABP1 is associated with several diseases, and single nucleotide variations in its gene can lead to various changes. Downregulation of FABP1 is seen in HCC tissues and could serve as a promising prognostic marker in HCC patients [29]. FABP1-targeting microRNAs could significantly reduce FABP1 expression at translational level and ameliorate hepatocyte steatosis and injury [30]. Women with polycystic ovary syndrome having FABP1 rs2197076 GG genotype had higher Ferriman 
Gallwey score and lower lipid accumulation product index than the AA+AG genotype carriers [31]. Substitution from adenine to guanine at 2919872 position, significantly reduced serum triglyceride concentration and FABP1 promoter activity [32]. T94A variant in FABP1 was related with elevated plasma triglycerides, increased cholesterol accumulation, atherothrombotic cerebral infarction and NAFLD by altering FABP1 structure, stability and conformational and functional response to fibrates [33].

Here, we performed a study to investigate the role of $F A B P 1$ rs1545224 and rs2241883 polymorphisms in CHB-related LC and HCC. Rs1545224 and rs2241883 polymorphisms represent an $A / G$ and a $\mathrm{C} / \mathrm{T}$ single-nucleotide variation on human chromosome 2, respectively. The transversion leads to an intronic variation of rs1545224 polymorphism and missense mutation of rs2241883 polymorphism. A previous study found both rs1545224 A allele and rs2241883 C allele were risk factors for NAFLD and showed a cumulative effect [17]. Increased levels of low density lipoprotein and fasting plasma glucose were observed in individuals with rs1545224 A allele and rs2241883 C allele respectively [17]. However, until now, the effect of FABP1 rs1545224 and rs2241883 polymorphisms on CHB-related LC and HCC has not been reported. By this case-control study, we found the two polymorphisms were not associated with LC or HCC risk in healthy individuals or $\mathrm{CHB}$ carriers. Even after adjusting for confounding factors like smoking and drinking history, gender, and age, the results did not change significantly. However, for patients with LC, rs1545224 A allele, AG and AA genotypes increased the risk of developing HCC to 1.33, 1.61 and 1.71 times respectively to those with G allele and GG genotype. However, a meaningful difference was only found in the dominant model after adjustment. Though intron polymorphisms may have little effect on gene function, they may influence transcription factor binding and even alter related protein expression [34]. Intronic variation in rs1545224 may change FABP1 expression, and increased expression of FABP1 was detected in liver cirrhosis patients' plasma and HCC tissues than those in health controls [16, 35].

Table 4. Association between FABPI polymorphisms and LC and HCC risk

\begin{tabular}{|c|c|c|c|c|c|c|c|c|c|c|}
\hline Model & LC vs. Controls & & HCC vs. Contre & & LC vs. CHB & & HCC vs. CHB & & HCC vs. LC & \\
\hline Rs1545224 & $\begin{array}{l}\text { OR } \\
(95 \% \mathrm{CI})\end{array}$ & $\mathbf{P}$ & $\begin{array}{l}\text { OR } \\
(95 \% \mathrm{CI})\end{array}$ & $\mathbf{P}$ & $\begin{array}{l}\text { OR } \\
(95 \% \mathrm{CI})\end{array}$ & $\mathbf{P}$ & $\begin{array}{l}\text { OR } \\
(95 \% \mathrm{CI})\end{array}$ & $\mathbf{P}$ & $\begin{array}{l}\text { OR } \\
(95 \% \mathrm{CI})\end{array}$ & $\mathbf{P}$ \\
\hline \multicolumn{11}{|l|}{ Allele } \\
\hline G & $1^{\text {ref }}$ & 0.25 & $1^{\text {ref }}$ & 0.28 & $1^{\text {ref }}$ & 0.25 & $1^{\text {ref }}$ & 0.28 & 1 ref & 0.03 \\
\hline A & $0.86(0.67-1.11)$ & & $\begin{array}{l}1.15 \\
(0.89-1.47)\end{array}$ & & $\begin{array}{l}0.87 \\
(0.67-1.11)\end{array}$ & & $\begin{array}{l}1.15 \\
(0.89-1.47)\end{array}$ & & $1.33(1.03-1.79)$ & \\
\hline \multicolumn{11}{|c|}{ Codominant model } \\
\hline GG & $1^{\text {ref }}$ & & $1^{\text {ref }}$ & & $1^{\text {ref }}$ & & $1^{\text {ref }}$ & & $1^{\text {ref }}$ & \\
\hline AG & $0.92(0.61-1.38)$ & 0.69 & $\begin{array}{l}1.48 \\
(0.97-2.26)\end{array}$ & 0.07 & $\begin{array}{l}0.87 \\
(0.58-1.31)\end{array}$ & 0.51 & $\begin{array}{l}1.40 \\
(0.92-2.14)\end{array}$ & 0.12 & $1.61(1.06-2.44)$ & 0.03 \\
\hline AA & $0.75(0.46-1.23)$ & 0.26 & $\begin{array}{l}1.29 \\
(0.79-2.11)\end{array}$ & 0.31 & $\begin{array}{l}0.76 \\
(0.46-1.24)\end{array}$ & 0.27 & $\begin{array}{l}1.30 \\
(0.79-2.13)\end{array}$ & 0.30 & $\begin{array}{l}1.71 \\
(1.03-2.82)\end{array}$ & 0.04 \\
\hline \multicolumn{11}{|c|}{ Dominant model } \\
\hline GG & $1^{\text {ref }}$ & 0.44 & $1^{\text {ref }}$ & 0.09 & $1^{\text {ref }}$ & 0.35 & $1^{\text {ref }}$ & 0.12 & $1^{\text {ref }}$ & 0.01 \\
\hline $\mathrm{AG}+\mathrm{AA}$ & $0.86(0.59-1.26)$ & & $1.41(0.95-2.10)$ & & $0.84(0.57-1.22)$ & & $1.37(0.92-2.04)$ & & $1.64(1.11-2.43)$ & \\
\hline \multicolumn{11}{|c|}{ Recessive model } \\
\hline $\mathrm{AG}+\mathrm{GG}$ & $1^{\text {ref }}$ & 0.28 & $1^{\mathrm{ref}}$ & 1 & $1^{\text {ref }}$ & 0.37 & $1^{\text {ref }}$ & 0.85 & $1^{\text {ref }}$ & 0.28 \\
\hline AA & $0.79(0.52-1.21)$ & & $1(0.66-1.51)$ & & $0.82(0.54-1.26)$ & & $1.04(0.69-1.57)$ & & $1.26(0.83-1.93)$ & \\
\hline Rs2241883 & $\begin{array}{l}\text { OR } \\
(\mathbf{9 5} \% \mathrm{CI})\end{array}$ & $\mathbf{P}$ & $\begin{array}{l}\text { OR } \\
(95 \% \mathrm{CI})\end{array}$ & $\mathbf{P}$ & $\begin{array}{l}\text { OR } \\
\text { (95\%CI) }\end{array}$ & $\mathbf{P}$ & $\begin{array}{l}\text { OR } \\
(\mathbf{9 5} \% \mathrm{CI})\end{array}$ & $\mathbf{P}$ & $\begin{array}{l}\text { OR } \\
(95 \% \mathrm{CI})\end{array}$ & $\mathbf{P}$ \\
\hline \multicolumn{11}{|l|}{ Allele } \\
\hline $\mathrm{T}$ & $1^{\text {ref }}$ & 0.12 & $1^{\mathrm{ref}}$ & 0.79 & $1^{\text {ref }}$ & 0.27 & $1^{\text {ref }}$ & 0.85 & $1^{\mathrm{ref}}$ & 0.20 \\
\hline C & $0.78(0.58-1.07)$ & & $0.96(0.71-1.30)$ & & $0.84(0.62-1.14)$ & & $1.03(0.76-1.39)$ & & $1.23(0.90-1.67)$ & \\
\hline \multicolumn{11}{|c|}{ Codominant model } \\
\hline $\mathrm{TT}$ & $1^{\text {ref }}$ & & 1 ref & & $1^{\text {ref }}$ & & $1^{\text {ref }}$ & & 1 ref & \\
\hline $\mathrm{CT}$ & $0.81(0.55-1.18)$ & 0.27 & $0.88(0.60-1.29)$ & 0.52 & $0.82(0.56-1.20)$ & 0.30 & $0.90(0.61-1.31)$ & 0.57 & $\begin{array}{l}1.09 \\
(0.74-1.60)\end{array}$ & 0.65 \\
\hline $\mathrm{CC}$ & $0.56(0.22-1.38)$ & 0.20 & $1.11(0.51-2.41)$ & 0.79 & $0.72(0.29-1.93)$ & 0.54 & $1.48(0.65-3.40)$ & 0.35 & $\begin{array}{l}2.00 \\
(0.82-4.84)\end{array}$ & 0.12 \\
\hline \multicolumn{11}{|c|}{ Dominant model } \\
\hline TT & $1^{\text {ref }}$ & 0.17 & $1^{\text {ref }}$ & 0.62 & $1^{\text {ref }}$ & 0.26 & $1^{\text {ref }}$ & 0.81 & $1^{\text {ref }}$ & 0.38 \\
\hline $\mathrm{CT}+\mathrm{CC}$ & $0.78(0.533-1.12)$ & & $0.91(0.64-1.31)$ & & $0.81(0.56-1.17)$ & & $0.96(0.67-1.37)$ & & $1.18(0.82-1.70)$ & \\
\hline \multicolumn{11}{|c|}{ Recessive model } \\
\hline $\mathrm{CT}+\mathrm{TT}$ & $1^{\text {ref }}$ & 0.26 & 1 ref & 0.71 & $1^{\text {ref }}$ & 0.63 & 1 ref & 0.30 & 1 ref & 0.13 \\
\hline $\mathrm{CC}$ & $0.60(0.24-1.47)$ & & $1.16(0.54-2.49)$ & & $0.79(0.31-2.04)$ & & $1.54(0.68-3.49)$ & & $1.23(0.81-4.66)$ & \\
\hline
\end{tabular}

CHB, chronic hepatitis B; LC, liver cirrhosis; HCC, hepatocellular carcinoma; OR, odd ratio; 95\%CI, 95\% confidence interval 
Table 5. Association between FABPI polymorphisms and LC and HCC risk adjusted by gender, age, smoking and drinking

\begin{tabular}{|c|c|c|c|c|c|c|c|c|c|c|}
\hline \multirow{2}{*}{$\begin{array}{l}\text { Model } \\
\text { Rs1545224 }\end{array}$} & \multicolumn{2}{|l|}{ LC vs. Controls } & \multicolumn{2}{|c|}{ HCC vs. Controls } & \multicolumn{2}{|l|}{ LC vs. CHB } & \multicolumn{2}{|l|}{ HCC vs. CHB } & \multicolumn{2}{|l|}{ HCC vs. LC } \\
\hline & $\begin{array}{l}\text { OR* } \\
\left(95 \% C^{*}\right)\end{array}$ & $\mathbf{P}^{*}$ & $\begin{array}{l}\mathrm{OR}^{*} \\
\left(95 \% \mathrm{CI}^{*}\right)\end{array}$ & $\mathbf{P}^{*}$ & $\begin{array}{l}\text { OR* } \\
\left(95 \% \mathrm{CI}^{*}\right)\end{array}$ & $\mathbf{P}^{*}$ & $\begin{array}{l}\mathrm{OR}^{*} \\
\left(95 \% \mathrm{CI}^{*}\right)\end{array}$ & $P^{*}$ & $\begin{array}{l}\mathrm{OR}^{*} \\
\left(95 \% \mathrm{CI}^{*}\right)\end{array}$ & $\mathbf{P}^{*}$ \\
\hline \multicolumn{11}{|l|}{ Allele } \\
\hline G & $1^{\text {ref }}$ & 0.81 & $1^{\text {ref }}$ & 0.32 & $1^{\mathrm{ref}}$ & 0.42 & $1^{\text {ref }}$ & 0.35 & $1^{\text {ref }}$ & 0.07 \\
\hline A & $0.96(0.71-1.31)$ & & $1.17(0.86-1.59)$ & & $0.90(0.69-1.17)$ & & $1.16(0.85-1.58)$ & & $1.30(0.98-1.72)$ & \\
\hline \multicolumn{11}{|c|}{ Codominant model } \\
\hline GG & 1 ref & & $1^{\text {ref }}$ & & 1 ref & & 1 ref & & $1^{\mathrm{ref}}$ & \\
\hline AG & $0.89(0.54-1.48)$ & 0.66 & $1.23(0.73-2.08)$ & 0.43 & $0.99(0.64-1.55)$ & 0.97 & $1.68(0.99-2.85)$ & 0.05 & $1.57(0.99-2.49)$ & 0.06 \\
\hline AA & $0.94(0.51-1.75)$ & 0.86 & $1.36(0.73-2.52)$ & 0.33 & $0.79(0.46-1.36)$ & 0.39 & $1.32(0.71-2.45)$ & 0.39 & $1.63(0.93-2.85)$ & 0.09 \\
\hline \multicolumn{11}{|c|}{ Dominant model } \\
\hline GG & 1 ref & 0.69 & $1^{\text {ref }}$ & 0.34 & 1 ref & 0.70 & 1 ref & 0.08 & 1ref & 0.04 \\
\hline $\mathrm{AG}+\mathrm{AA}$ & $0.91(0.57-1.45)$ & & $1.27(0.78-2.08)$ & & $0.92(0.61-1.40)$ & & $1.55(0.94-2.55)$ & & 1.59 (1.03-2.46) & \\
\hline \multicolumn{11}{|c|}{ Recessive model } \\
\hline $\mathrm{AG}+\mathrm{GG}$ & $1^{\mathrm{ref}}$ & 0.98 & $1^{\text {ref }}$ & 0.52 & 1 ref & 0.33 & 1 ref & 0.81 & 1ref & 0.41 \\
\hline AA & $1.01(0.58-1.74)$ & & $1.19(0.71-1.99)$ & & $0.79(0.49-1.27)$ & & $0.94(0.56-1.57)$ & & $1.22(0.76-1.97)$ & \\
\hline Rs2241883 & $\begin{array}{l}\text { OR* } \\
\left(95 \% \mathrm{CI}^{*}\right)\end{array}$ & $P^{*}$ & $\begin{array}{l}\mathrm{OR}^{*} \\
\left(95 \% \mathrm{CI}^{*}\right)\end{array}$ & $P^{*}$ & $\begin{array}{l}\mathrm{OR}^{*} \\
\left(95 \% \mathrm{CI}^{*}\right)\end{array}$ & $\mathbf{P}^{*}$ & $\begin{array}{l}\mathrm{OR}^{*} \\
\left(95 \% \mathrm{CI}^{*}\right)\end{array}$ & $P^{*}$ & $\begin{array}{l}\mathrm{OR}^{*} \\
\left(95 \% \mathrm{CI}^{*}\right)\end{array}$ & $P^{*}$ \\
\hline \multicolumn{11}{|l|}{ Allele } \\
\hline $\mathrm{T}$ & $1^{\mathrm{ref}}$ & 0.40 & $1^{\text {ref }}$ & 0.31 & $1^{\text {ref }}$ & 0.44 & $1^{\text {ref }}$ & 0.90 & $1^{\text {ref }}$ & 0.30 \\
\hline C & $0.85(0.58-1.25)$ & & $0.83(0.57-1.20)$ & & $0.87(0.62-1.23)$ & & $1.03(0.71-1.49)$ & & $1.20(0.86-1.67)$ & \\
\hline \multicolumn{11}{|c|}{ Codominant model } \\
\hline TT & 1 ref & & $1^{\text {ref }}$ & & 1 ref & & 1 ref & & 1 ref & \\
\hline $\mathrm{CT}$ & $0.8(0.54-1.43)$ & 0.61 & $0.81(0.51-1.30)$ & 0.38 & $0.83(0.55-1.26)$ & 0.38 & $0.87(0.54-1.41)$ & 0.57 & $1.07(0.70-1.64)$ & 0.75 \\
\hline $\mathrm{CC}$ & $0.65(0.22-1.94)$ & 0.44 & $0.72(0.27-1.92)$ & 0.51 & $0.89(0.33-2.44)$ & 0.82 & $1.50(0.55-4.09)$ & 0.43 & $1.85(0.72-4.76)$ & 0.20 \\
\hline \multicolumn{11}{|c|}{ Dominant model } \\
\hline TT & 1 ref & 0.48 & $1^{\text {ref }}$ & 0.32 & 1 ref & 0.39 & $1^{\text {ref }}$ & 0.79 & 1 ref & 0.49 \\
\hline $\mathrm{CT}+\mathrm{CC}$ & $0.85(0.53-1.35)$ & & $0.80(0.51-1.25)$ & & $0.84(0.56-1.25)$ & & $0.94(0.60-1.48)$ & & $1.16(0.77-1.73)$ & \\
\hline \multicolumn{11}{|c|}{ Recessive model } \\
\hline $\mathrm{CT}+\mathrm{TT}$ & $1^{\text {ref }}$ & 0.48 & $1^{\text {ref }}$ & 0.61 & $1^{\text {ref }}$ & 0.92 & $1^{\text {ref }}$ & 0.37 & $1^{\text {ref }}$ & 0.21 \\
\hline $\mathrm{CC}$ & $0.68(0.23-2.00)$ & & $0.77(0.29-2.04)$ & & $0.95(0.35-2.57)$ & & $1.58(0.59-4.24)$ & & $1.81(0.71-4.60)$ & \\
\hline
\end{tabular}

$\mathrm{CHB}$, chronic hepatitis B; LC, liver cirrhosis; HCC, hepatocellular carcinoma; OR, odd ratio; $95 \% \mathrm{CI}$, 95\% confidence interval; OR*, OR values adjusted by gender, age, smoking and drinking; $\mathrm{P}^{*}, \mathrm{P}$ values adjusted by gender, age, smoking and drinking.

Although in this study, we first investigated the association between FABP1 rs1545224 and rs2241883 polymorphisms and HBC-related liver diseases, there are still some limitations. Firstly, all patients were from the same area, which may result in a poor representation. Secondly, in addition to genetic polymorphisms, other factors such as lifestyle and geographical environmental factors have also played an important role in the development from HBV to LC or HCC. We have not been able to study the effects of these factors. Finally, we only found rs1545224 polymorphism may be related to the development of HCC in LC patients, but the mechanisms have not been studied.

To summarize, our results revealed that though neither, FABP1 rs1545224 or rs2241883 polymorphisms, influence the susceptibility of LC and HCC in healthy individuals or CHB carriers, FABP1 rs1545224 polymorphism might contribute to increased HCC risk in LC patients, suggesting that FABP1 rs1545224 polymorphism may be related to the process of developing HCC in Chinese patients with LC.

\section{Acknowledgements}

This work was supported by the National Natural Science Foundation of China (No.81471670), and the Key research and development plan, Shaanxi Province, China (2017ZDXM-SF-066).

\section{Competing Interests}

The authors have declared that no competing interest exists.

\section{References}

1. Trepo C, Chan HL, Lok A. Hepatitis B virus infection. Lancet (London, England). 2014; 384: 2053-63.

2. Soriano V, Young B, Reau N. Report from the International Conference on Viral Hepatitis - 2017. AIDS reviews. 2018; 20: 58-70.

3. Chen W, Zheng R, Baade PD, et al. Cancer statistics in China, 2015. CA: a cancer journal for clinicians. 2016; 66: 115-32.

4. Stanaway JD, Flaxman AD, Naghavi M, et al. The global burden of viral hepatitis from 1990 to 2013: findings from the Global Burden of Disease Study 2013. Lancet (London, England). 2016; 388: 1081-8.

5. Croagh CM, Lubel JS. Natural history of chronic hepatitis B: phases in a complex relationship. World journal of gastroenterology. 2014; 20: 10395-404.

6. McMahon BJ. The natural history of chronic hepatitis B virus infection. Hepatology (Baltimore, Md). 2009; 49: S45-55.

7. Ma N, Zhang X, Yang L, et al. Role of Functional IFNL4, IFNLR1, IFNA, IFNAR2 Polymorphisms in Hepatitis B virus-related liver disease in Han Chinese population. Journal of viral hepatitis. 2018; 25: 306-13.

8. Li Y, Zhai Y, Song Q, et al. Genome-Wide Association Study Identifies a New Locus at 7q21.13 Associated with Hepatitis B Virus-Related Hepatocellular Carcinoma. Clinical cancer research : an official journal of the American Association for Cancer Research. 2018; 24: 906-15.

9. Chen SH, Van Tuinen P, Ledbetter DH, et al. Human liver fatty acid binding protein gene is located on chromosome 2 . Somatic cell and molecular genetics. 1986; 12: 303-6.

10. Smathers RL, Petersen DR. The human fatty acid-binding protein family: evolutionary divergences and functions. Human genomics. 2011; 5: 170-91.

11. Mukai T, Egawa M, Takeuchi T, et al. Silencing of FABP1 ameliorates hepatic steatosis, inflammation, and oxidative stress in mice with nonalcoholic fatty liver disease. FEBS open bio. 2017; 7: 1009-16. 
12. Martin GG, Landrock D, Dangott LJ, et al. Human Liver Fatty Acid Binding Protein-1 T94A Variant, Nonalcohol Fatty Liver Disease, and Hepatic Endocannabinoid System. Lipids. 2018; 53: 27-40.

13. Wu YL, Peng XE, Zhu YB, et al. Hepatitis B Virus X Protein Induces Hepatic Steatosis by Enhancing the Expression of Liver Fatty Acid Binding Protein. Journal of virology. 2016; 90: 1729-40.

14. He J, Zeng YL, Li W, et al. Clinical study of non-alcoholic fatty liver disease and its combined the chronic HBV infection. Chinese journal of hepatology. 2017; 25: 618-22.

15. Hui RWH, Seto WK, Cheung KS, et al. Inverse relationship between hepatic steatosis and hepatitis B viremia: Results of a large case-control study. Journal of viral hepatitis. 2018; 25: 97-104.

16. $\mathrm{Ku} \mathrm{CY}$, Liu $\mathrm{YH}$, Lin $\mathrm{HY}$, et al. Liver fatty acid-binding protein (L-FABP) promotes cellular angiogenesis and migration in hepatocellular carcinoma. Oncotarget. 2016; 7: 18229-46.

17. Peng $\mathrm{XE}, \mathrm{Wu} \mathrm{YL}, \mathrm{Lu} \mathrm{QQ}$, et al. Two genetic variants in FABP1 and susceptibility to non-alcohol fatty liver disease in a Chinese population. Gene. 2012; 500: 54-8.

18. Ferreira Sda C, Chacha SG, Souza FF, et al. IL-18, TNF, and IFN-gamma alleles and genotypes are associated with susceptibility to chronic hepatitis B infection and severity of liver injury. Journal of medical virology. 2015; 87: $1689-96$.

19. Lu Y, Bao JG, Deng Y, et al. Role of IL-18 Gene Promoter Polymorphisms, Serum IL-18 Levels, and Risk of Hepatitis B Virus-related Liver Disease in the Guangxi Zhuang Population: a Retrospective Case-Control Study. Asian Pacific journal of cancer prevention : APJCP. 2015; 16: 6019-26.

20. Zhang QX, Yao YQ, Li SL, et al. Association between interleukin-18 gene polymorphisms and hepatocellular carcinoma caused by hepatitis B virus. Chinese journal of hepatology. 2016; 24: 352-7.

21. Zhu SL, Zhao Y, Hu XY, et al. Genetic polymorphisms -137 (rs187238) and -607 (rs1946518) in the interleukin-18 promoter may not be associated with development of hepatocellular carcinoma. Scientific reports. 2016; 6: 39404.

22. Dai ZJ, Liu XH, Kang HF, et al. Genetic Variation in Metastasis-Associated in Colon Cancer-1 and the Risk of Breast Cancer Among the Chinese Han Population: A STROBE-Compliant Observational Study. Medicine. 2016; 95: e2801.

23. Dai ZJ, Liu XH, Wang M, et al. IL-18 polymorphisms contribute to hepatitis B virus-related cirrhosis and hepatocellular carcinoma susceptibility in Chinese population: a case-control study. Oncotarget. 2017; 8: 81350-60.

24. Bennett ER, Reuter-Rice K, Laskowitz DT. Boca Raton, USA: Translational Research in Traumatic Brain Injury. CRC Press/Taylor and Francis Group Publisher; 2016

25. Zhang X, Zhai L, Rong C, Qin X, Li S. Association of Ghrelin Gene Polymorphisms and Serum Ghrelin Levels with the Risk of Hepatitis B Virus-Related Liver Diseases in a Chinese Population. PloS one. 2015; 10: e0143069.

26. Huang X, Li H, Wang J, et al. Genetic polymorphisms in Toll-like receptor 3 gene are associated with the risk of hepatitis $\mathrm{B}$ virus-related liver diseases in a Chinese population. Gene. 2015; 569: 218-24.

27. Jiang DK, Sun J, Cao G, et al. Genetic variants in STAT4 and HLA-DQ genes confer risk of hepatitis B virus-related hepatocellular carcinoma. Nature genetics. 2013; 45: 72-5.

28. Jiang DK, Ma XP, Wu X, et al. Genetic variations in STAT4,C2,HLA-DRB1 and HLA-DQ associated with risk of hepatitis B virus-related liver cirrhosis. Scientific reports. 2015; 5: 16278 .

29. Wang B, Tao X, Huang CZ, et al. Decreased expression of liver-type fatty acid-binding protein is associated with poor prognosis in hepatocellular carcinoma. Hepato-gastroenterology. 2014; 61: 1321-6.

30. Wu YL, Zhu YB, Huang RD, et al. Multiple MicroRNAs Ameliorate Hepatocyte Steatosis and Injury by Suppressing FABP1 Expression. Cellular physiology and biochemistry : international journal of experimental cellular physiology, biochemistry, and pharmacology. 2017; 44: 2243-55.

31. Rashid N, Nigam A, Saxena P, et al. Association of IL-1beta, IL-1Ra and FABP1 gene polymorphisms with the metabolic features of polycystic ovary syndrome. Inflammation research : official journal of the European Histamine Research Society [et al]. 2017; 66: 621-36.

32. Peng $\mathrm{XE}, \mathrm{Wu} \mathrm{YL}, \mathrm{Zhu} \mathrm{YB}$, et al. Association of a Human FABP1 Gene Promoter Region Polymorphism with Altered Serum Triglyceride Levels. PloS one. 2015; 10: e0139417.

33. Martin GG, McIntosh AL, Huang $\mathrm{H}$, et al. The human liver fatty acid binding protein T94A variant alters the structure, stability, and interaction with fibrates. Biochemistry. 2013; 52: 9347-57.

34. Tao $\mathrm{H}, \mathrm{Zhou} X, \mathrm{Xie} \mathrm{Q}$, et al. SRR intronic variation inhibits expression of its neighbouring SMG6 gene and protects against temporal lobe epilepsy. Journal of cellular and molecular medicine. 2018; 22: 1883-93.

35. Graupera I, Coll M, Pose E, et al. Adipocyte Fatty-Acid Binding Protein is Overexpressed in Cirrhosis and Correlates with Clinical Outcomes. Scientific reports. 2017; 7: 1829. 